\section{Acolhimento solidário ou atropelamento? A qualidade na relação profissional de saúde e paciente face à tecnologia informacional}

\author{
Sympathetic listening or steamrolling? \\ Quality in the health professional-patient \\ relationship in light of new information technology
}

\section{Setor de Ciências Sociais Aplicadas, Universidade Federal do Paraná, Curitiba, Brasil. \\ Correspondência Sandra Mara Maciel-Lima Setor de Ciências Sociais Aplicadas, Universidade Federal do Paraná. Av. Prefeito Lothário Meissner 3400, Curitiba, PR 80210-170, Brasil. sandramaciel@avalon.sul. com.br \\ sandralima@ufpr.br}

\begin{abstract}
In the services sector, the product of labor is not a commodity that can be traded easily. What is sold is a specialized service, basically through an exchange of information to meet the client's needs and expectations. What emerge are thus the social relations between individuals: professionals and clients/consumers. This article presents evidence that the introduction of information technology undermines the quality of the relationship between the health professional and the patient. The article begins by discussing concepts pertaining to quality in the health sector. The health professional-patient relationship is then discussed through a brief review of the health/disease concept and specifically the physician-patient relationship. Analysis of primary data shows some indication that technological, physical, and management changes in health care units are undermining the quality of health care: many technological changes, but few operational changes, and many machines, but few professionals to treat patients.
\end{abstract}

Quality of Health Care; Health Services; Technology

\section{Qualidade no atendimento à saúde}

Diversos fatores e tendências contribuíram para se buscar a qualidade dos serviços de saúde; em primeiro lugar, a crise fiscal do estado social e a necessidade de reduzir as despesas públicas; em segundo, a necessidade de se reduzir as queixas e os procedimentos judiciais encaminhados pelos pacientes insatisfeitos 1,2.

Com os déficits orçamentários os governos estão cortando e adiando programas necessários à população e a alternativa possível seria melhorar a maneira como é feito o trabalho nos setores públicos.

Para Tauile 3, o aumento da qualidade é um dos objetivos da introdução da microeletrônica no processo de trabalho, no entanto, é uma possibilidade que não se concretiza necessariamente para todos. Em parte, qualidade depende das especificações do produto final que pode, ou não, ter a ver com o fato de serem usados equipamentos automatizados pela microeletrônica em sua produção. No caso do serviço público, o que se pretende é a qualidade dos serviços prestados.

Uma das razões, consideradas por Andreassi 4, para a baixa eficácia da inovação em serviços é que: "a tecnologia, por si só, não tem um peso fundamental no desempenho corporativo e na lucratividade da empresa de serviços. $\mathrm{Na}$ indústria, a introdução de uma inovação permite que a empresa obtenha uma vantagem 
competitiva significativa, tanto por oferecer um produto diferenciado como em razão de ele apresentar um custo menor. Em serviços, as habilidades e capacitações dos funcionários desempenham um papel central. Um cliente mal atendido raramente retorna a uma loja ou restaurante, mesmo se o preço for bom".

Em serviços de saúde, em especial, a tecnologia é apenas um instrumento de trabalho para os profissionais, pois o produto final de seu trabalho não é um bem físico e sim um bem, digamos assim, humanístico. O que se deve priorizar é a relação profissional-paciente e não profissional-máquina.

Ainda segundo o autor, a maneira de se inovar na indústria e em serviços é diferente. Em serviços a inovação de processo precede a inovação do produto. O primeiro estágio consiste na inovação do processo por meio de novas tecnologias para aumentar a eficiência na produção ou entrega de serviços existentes. O segundo estágio é marcado pela melhoria na qualidade do serviço prestado como resultado dos novos sistemas de produção ou entrega dos serviços. Somente neste ponto é que novos produtos ou serviços são criados com base na inovação tecnológica.

No entendimento de Almeida 5, a melhoria na qualidade do serviço prestado é cumprir com o especificado, fazer com que o cliente nos considere melhor do que os concorrentes, em todos os aspectos que ele julgue importantes.

Para Eiglier \& Langeard (1988, apud Serapioni 1), entretanto, a qualidade é constituída de dois elementos: um objetivo, relacionado aos componentes físicos do produto, e outro subjetivo, relacionado à satisfação do usuário, do ponto de vista da sua percepção e das suas expectativas. Como no caso dos serviços não há separação entre produção e distribuição, a qualidade se resumiria à satisfação do cliente em determinada situação.

No entanto, outros autores não compartilham esta definição, segundo eles, a avaliação da qualidade nos serviços de saúde deve levar em consideração não só a satisfação dos usuários, mas também, a satisfação dos profissionais e a eficácia do cuidado médico. Neste caso seria preciso também considerar outros fatores como a aceitabilidade, a adequação do processo de diagnóstico e da terapia, o comportamento dos médicos e dos outros profissionais diante dos pacientes, a rapidez na resposta ao requerimento do tratamento etc. 1 . Pois a mesma satisfação dos funcionários, co- mo clientes internos, é determinante para a qualidade dos serviços.

Segundo Almeida 5 (p. 8), não se pode substituir "mau atendimento por miçangas", da mesma forma que não se pode saltar etapas. "Antes de construirmos uma casa segura e adequada às nossas expectativas, até mesmo bela, por um preço que podemos pagar, temos que construir seus alicerces, e bem". No caso dos alicerces da qualidade, estamos falando em seriedade, visão, liderança pessoal, perseverança, treinamento e participação de todos, respeito pelos empregados, fornecedores e clientes - no nosso caso, respeito por toda a comunidade atendida.

Um processo de melhoria de qualidade, então, engloba todos os requisitos citados anteriormente, para buscar e garantir a satisfação dos nossos clientes-usuários.

Da mesma forma que na fábrica ou na indústria, o funcionário não é auto-suficiente, "ele precisa de treinamento, de equipamento, não de peças, mas de informações, procedimentos, dados, relatórios, para também executar a sua parcela..." 5 (p. 17).

Outro elemento essencial para atingir a qualidade nos serviços é o comprometimento dos profissionais de saúde com o trabalho. Conforme Barbosa \& Faria 6 (p. 4), “comprometimento poderia ser identificado, neste sentido, como engajamento ou disposição plena e espontânea para trabalhar, sentimento de responsabilidade pelo resultado e a plicação de esforços, criatividade e inovação para contornar os problemas $e$ garantir o sucesso e o resultado. Estar comprometido significa estar movido pelo desejo de ver o trabalho concluído e o objetivo atingido da melhor, mais eficiente, eficaz e efetiva maneira. É sentir-se realmente responsável e demonstrar desejo de ver o sucesso da ação".

O maior ou menor comprometimento com o trabalho está diretamente relacionado com a melhor qualidade da relação funcionário-usuário. E esta qualidade depende, sobretudo, do reconhecimento das necessidades dos funcionários no desempenho de suas funções, pois a mesma satisfação dos funcionários, enquanto clientes internos, é determinante para a qualidade dos serviços.

\section{A relação médico-paciente}

Os conceitos de saúde-doença, assim como as atividades de assistência médica e de enfermagem no Brasil, foram estudados por Lakatos \& 
Brutscher 7, e seu histórico dividido em dois momentos distintos: sociedades pré-capitalistas e sociedades capitalistas.

No período pré-capitalista, a prática médica estava ligada à constituição de um saber "esotérico", definido por um corpo particular de conhecimentos e de técnicas desconhecidas pela maior parte da população. Este saber, por sua vez, propiciava poder e prestígio a quem o possuía. Por sua vez, a prática da enfermagem pré-profissional, assim chamada pelos autores, surgiu no período pré-capitalista e parte do capitalista, com uma prática social iniciada com a divisão sexual do trabalho, atribuindo à mulher as atividades domésticas e, dentre elas, o cuidado com os doentes.

A transformação do modo de produção capitalista força o Estado a assumir, paulatinamente, as funções de cuidados médicos e de controle. Nesse modo de produção, a medicina perde seu caráter religioso, para articular-se direta ou indiretamente com a esfera produtiva. Não é mais a salvação das almas, mas a conservação e adaptação da força de trabalho às exigências de uma economia de reprodução ampliada. A saúde a serviço do capitalismo.

Em estudo realizado no setor de saúde municipal de Minas Gerais, Cotta et al. 8 mostram que, além das ações do serviço de saúde não terem sido alteradas, de curativas-individuais para coletivas-preventivas, o setor público também passou a priorizar as intervenções curativas. O locus de prestação de serviços curativos foi transferido do hospital para os postos de saúde públicos. Em conseqüência, o setor público implementou os serviços que seguem a lógica da produção-produtividade. Em suma, o importante, mais uma vez, é a quantidade em detrimento da qualidade de atendimento à população.

Isso é revelado por meio da imprensa que noticia, por um lado, os avanços da medicina e, por outro, o rompimento da tradicional relação médico-paciente. Os processos, denúncias e escândalos envolvendo médicos, odontólogos, psicólogos, enfermeiros são cada vez mais freqüentes, revelando o estranhamento das partes no que diz respeito à ética, à confiança e à credibilidade no tratamento proposto. "A cumplicidade até então existente entre as partes foi rompida" 9 (p. 56).

A subjetividade, característica peculiar da relação médico-paciente, cede lugar à objetividade racionalizadora. Obedecendo às novas normas administrativas, os médicos e os enfermeiros são compelidos a adotar atitudes que mais os assemelham a técnicos burocraticamente controlados do que a profissionais que detêm autonomia técnica. Preenchendo fichas, prontuários e seguindo as normas preestabelecidas pela administração, eles acabam por se aproximar das características de um "despachante" da saúde 9 e, com a introdução do sistema informatizado de atendimento, um despachante informatizado da saúde. Mais ainda, ao se caracterizar o médico como despachante, está-se admitindo, em última análise, a precarização da qualidade do trabalho médico.

O desafio do setor de saúde será o de esclarecer e superar o mito de que os serviços prestados pelas instituições públicas são de má qualidade, realizados por profissionais desqualificados. Pois, ao contrário do que se pensa, são serviços de excelência, com uso de equipamentos e tecnologia de ponta e executados por profissionais qualificados que, na sua segunda jornada de trabalho, exercem atividades semelhantes nas instituições privadas. Resta saber, se esta "excelência" dos serviços é sentida pelo usuário/paciente do serviço assistencial público, como por exemplo, após a informatização das Unidades de Saúde.

\section{Metodologia}

O presente artigo é parte da Dissertação de Mestrado da autora (defendida em junho de 2002), resultado de pesquisa realizada nas Unidades de Saúde do Município de Curitiba, no período de 1o de outubro a 19 de novembro de 2001. O objetivo da pesquisa foi o de verificar os impactos da tecnologia informacional sobre as relações de trabalho no setor de saúde.

Desde fevereiro de 1999, a Secretaria Municipal de Saúde do Município de Curitiba (SMSCuritiba), vem implantando gradativamente a informatização da rede própria e a adoção do prontuário eletrônico nas unidades de saúde. Sendo assim, no contexto do presente artigo, considera-se a informatização dos processos de trabalho nas unidades de saúde, chamado Cartão Qualidade-Saúde, como uma mudança em tecnologia física e a implementação do programa Acolhimento Solidário como uma mudança em tecnologia de gestão 10 .

Procurou-se, por meio de entrevistas semiestruturadas e aplicação de formulários Escala Likert, coletar o maior número de informações, com o propósito de apreender a globalidade da situação. A população de interesse da pesquisa foi constituída pelos profissionais de saúde auxiliares de enfermagem, enfermeiros e médicos - lotados nas 88 Unidades de Saúde já informatizadas no Município de Curitiba (dados de setembro de 2001), que exerciam sua função 
desde 1998. Profissionais esses, que contribuíram com experiências adquiridas antes, durante e depois da informatização.

\section{Impactos da tecnologia informacional}

Os impactos da tecnologia informacional sobre a qualidade no atendimento assistencial nas Unidades de Saúde podem ser observados na Tabela 1. Essa Tabela traz informações acerca de alguns indicadores de qualidade e/ou precariedade no atendimento médico, corroborando a hipótese de Machado 9, a do distanciamento entre médico e paciente.

Dos profissionais pesquisados, $73,2 \%$ concordam que a relação entre profissional de saúde e paciente tornou-se mais distante com a introdução do sistema informatizado, sendo que este percentual corresponde a $89,4 \%$ dos médicos, $78,1 \%$ dos enfermeiros e $65,9 \%$ dos auxiliares de enfermagem (Tabela 2 ).

Observa-se uma preocupação maior dos médicos quanto à distância. Neste particular, o computador poderia ser comparado a um intruso no relacionamento entre profissional-paciente.

Uma outra questão da Tabela 1 possibilita confirmarmos que os profissionais percebem a mudança no trato com os pacientes. Os dados mostram que $60,8 \%$ dos profissionais concordam que após a informatização o profissional de saúde ficou mais distante, pois não pode dar mais atenção às suas queixas. E, neste caso, mais uma vez, o percentual dos médicos concordantes com esta questão é de $80,3 \%$ contra $65,6 \%$ dos enfermeiros e $52,1 \%$ dos auxiliares de enfermagem (Tabela 3 ). O percentual significativo dos médicos está sendo motivado pela seguinte percepção: “uma parte do tempo do médico foi seqüestrada pela máquina” (Médico, Unidade de Saúde 25).

Outros depoimentos dos profissionais envolvidos no atendimento à saúde servem para, não só ilustrar, mas reforçar os números apresentados: [o relacionamento com o usuário] "hoje está mais difícil, você tem que ficar olhando pra tela... prestando atenção no que você está escrevendo...[risadas] e antes a gente tinha mais tempo, ou você faz ou fica conversando com o paciente..." (Auxiliar de Enfermagem 4); “...eu acho que houve uma distância entre o profissional e o paciente. Porque a gente se preocupa tanto com a tela; e o paciente, ele fica mais inibido em falar porque ele acha... ah... vamos falar a verdade... a gente só fala quando alguém olha nos olhos... principalmente quando você está com dor, o paciente quer que você acredite que ele está com dor.. e com o computador você fica olhando pra tela e 'o que o senhor tem?'Sabe...tira aquele laço do paciente com ofuncionário" (Enfermeiro 3, Unidade de Saúde 12).

A ruptura do laço entre profissional e paciente põe em dúvida a qualidade do atendimento porque contraria o conceito de qualidade de Serapioni 1, cujo pressuposto é o de que para haver qualidade no serviço, todos, clientes, acionistas, funcionários e comunidade devem estar satisfeitos, o laço não pode estar quebrado, portanto.

"Mas para o atendimento eu acho assim muito triste, porque o próprio paciente sente... sabe. Eu vejo até a angústia dos funcionários em si, de ter que ficar mexendo no computador, e o paciente... você entra no programa, você clica várias vezes, aí quando você chama o paciente, tem que salvar que o paciente tá ali; aí faz o

Tecnologia e qualidade: a perspectiva do profissional de saúde.

\begin{tabular}{lcc}
\hline Categoria & Discordo (\%) & Concordo (\%) \\
\hline A relação entre o profissional de saúde e o paciente tornou-se mais distante & 26,8 & 73,2 \\
O preenchimento dos dados no computador interfere no atendimento ao paciente & 38,9 & 12,8 \\
Aumentou o registro de atendimentos & 83,8 & 87,1 \\
Não há prioridade no atendimento de pessoas com necessidade imediatas & 18,9 & 31,1 \\
Ainda há "burocracia" no atendimento & 39,2 & 60,8 \\
O profissional de saúde ficou mais distante do paciente pois não pode & 12,5 \\
dar mais atenção às suas queixas & 76,2 \\
Ainda há filas de espera & 74,7 \\
O acesso aos programas da Secretaria Municipal de Saúde não se torna facilitado & 87,5 \\
Ficou mais difícil agendar consultas com especialistas & 23,8 \\
\hline
\end{tabular}

Fonte: dados primários. 
Relação mais distante entre profissional e usuário.

\begin{tabular}{lcccc}
\hline Categoria & $\begin{array}{l}\text { Auxiliar de } \\
\text { enfermagem (\%) }\end{array}$ & Enfermeiro (\%) & Médico (\%) & Total (\%) \\
\hline Discordo & 34,1 & 21,9 & 10,6 & 26,8 \\
Concordo & 65,9 & 78,1 & 89,4 & 73,2 \\
Total & 100,0 & 100,0 & 100,0 & 100,0 \\
\hline
\end{tabular}

Fonte: dados primários.

Tabela 3

O profissional está mais distante.

\begin{tabular}{lccrr}
\hline Categoria & $\begin{array}{c}\text { Auxiliar de } \\
\text { enfermagem (\%) }\end{array}$ & Enfermeiro (\%) & Médico (\%) & Total (\%) \\
\hline Discordo totalmente & 47,9 & 34,4 & 19,7 & 39,2 \\
Concordo totalmente & 52,1 & 65,6 & 80,3 & 60,8 \\
Total & 100,0 & 100,0 & 100,0 & 100,0 \\
\hline
\end{tabular}

Fonte: dados primários

atendimento ... tudo rápido... verificou pressão, vai direto digitar... você não tem um comentário de como está esta pressão...sabe, eu acho assim que a máquina prendeu muito o funcionário e deixou a parte do laço de lado" (Enfermeiro 3, Unidade de Saúde 12).

"Hoje você não pode ficar olhando pro paciente, eu não consigo digitar olhando pro paciente, então você tá digitando e você dá uma olhadinha. Porque você não consegue ficar olhando e daí você tem que prestar atenção pra você não errar no digitar, então não são todas as pessoas que conseguem prestar atenção no paciente e no computador..." (Auxiliar de Enfermagem 5, Unidade de Saúde 18).

"Eu acho que o paciente gostaria que eu ficasse olhando mais pra ele... então não só a mim, mas eles também falam do médico. Do médico ficar... mais ainda o médico do que a gente... tem que ficar olhando pra tela, pesquisando as coisas, então não dá tanta atenção pro paciente" (Auxiliar de Enfermagem 4).

"Eu acho que distanciou mais [profissional em relação ao paciente]” (Auxiliar de Enfermagem 3).

“Com relação ao profissional ficar mais próximo do paciente [médico respirou fundo... sorriu, engoliu e disse]: 'mais ou menos”' (Médico, Unidade de Saúde 24).
Quando o profissional responde "mais ou menos”, após titubear, gaguejar, demonstra claramente como esta questão lhe incomoda. Outro profissional "acha ótimo a informatização desde que dê mais atenção ao profissional e ao paciente. O prontuário eletrônico dificulta o atendimento, não está adequado ao ritmo do médico; não é possível visualizar dados agregados de últimas consultas; o profissional tem que olhar consulta por consulta, procurando particularidades, avisos sobre o paciente" (Médico, Unidade de Saúde 25).

O distanciamento no relacionamento profissional-paciente foi sentido também pelos usuários, como relatado por esta enfermeira (Unidade de Saúde 13): "houve uma reclamação à Central de Atendimentos da Prefeitura de um paciente que, entre outras coisas, relatou: $a$ médica só olhava para o computador!". O paciente exige atenção dos médicos e demais profissionais, como disse uma senhora idosa, usuária do sistema: "doutor, isso agora parece uma firma e não um postinho de saúde" (Médico, Unidade de Saúde 26).

Os depoimentos acima vêm de encontro a outro dado revelado pela Tabela 1 , de que $61,1 \%$ dos profissionais concordam que o preenchimento dos dados no computador interfere no atendimento ao paciente. Os próprios profissio- 
nais justificam sua percepção por meio dos depoimentos reveladores: "interfere, pois o ideal é olhar no rosto da pessoa... os pacientes chegam até a Unidade carentes, precisando de atenção...e o computador acaba distanciando este contato" (Enfermeiro, Unidade de Saúde 13). A própria presença do computador em cima da mesa, como se demarcasse uma barreira tecnológica entre o profissional de saúde e o paciente ou, mais especificamente, entre o médico e o paciente, interfere na relação e no atendimento porque impõe tratamento do paciente não como sujeito, mas como algo desprovido de sua humanidade. Esta desumanização já foi até percebida por alguns profissionais como nos depoimentos que seguem: "porque você esquece, fica tão preso na parte burocrática [digitação dos dados] que o conteúdo da enfermagem, que é ver o todo do paciente, você já não tem mais... eu prefiro assim, passar isso pra minha equipe e... a parte mais importante é a relação do paciente, a parte de relacionamento. E no computador você já não consegue fazer isso, mesmo que você relate tudo que você faz com o paciente, é uma coisa fria, você tá lidando com uma máquina e o paciente, ele mesmo diz: 'olha parece que a gente é uma máquina aqui, tem que digitar pra sair"' (Enfermeiro 3, Unidade de Saúde 12).

"[O sistema] desumaniza o atendimento...eu tinha vontade de chutar a máquina" (Auxiliar de Enfermagem, Unidade de Saúde 14; "o sistema desumaniza o atendimento!" (Médico, Unidade de Saúde 13); “o trabalho está menos humanizado" (Auxiliar de Enfermagem, Unidade de Saúde 21).

O contraste entre humanização e desumanização no atendimento está bem caracterizado na percepção do profissional relatada no próximo depoimento: “às vezes o usuário chega com problemas, com dores, angústias e só com uma conversa melhora, mas com a falta de tempo das auxiliares, o paciente passa rapidamente pela triagem e vai para a consulta, o médico receita algum medicamento que, talvez,pudesse ser desnecessário se o paciente tivesse tido atenção anterior. Os pacientes ficam de lado. Parece mais um 'atropelamento solidário'e não 'acolhimento solidário”' (Auxiliar de Enfermagem, Unidade de Saúde 7).

O conjunto de depoimentos indica claramente o processo de precarização da qualidade no atendimento médico das Unidades de Saúde. Um atendimento que privilegia a quantidade em detrimento da qualidade.

Fica demonstrado que qualidade de serviço em geral e na saúde, em especial, não se define a partir de inovações técnicas apenas, conforme as análises de Tauile 3 e Andreassi 4.
Na Tabela 1, observamos que $87,2 \%$ dos profissionais concordam que com a informatização houve aumento no registro de atendimentos. O aumento pode ser justificado pela facilidade de controle e manutenção dos registros de atendimento na recepção das Unidades, mas também pode ser justificado pelo aumento da área de abrangência da maioria das Unidades do município. Não significa somente que com a informatização o número de pessoas atendidas pelas Unidades aumentou, não mesmo. Esse aumento pode ser melhor explicado pela nova gestão do processo de atendimento. Após a informatização, toda e qualquer pessoa que chega na Unidade, seja para marcar consulta, para pegar medicação ou para medir a pressão arterial, tem sua demanda registrada pelo computador. Desta forma, o número de registros nas Unidades aumentou consideravelmente, pois anteriormente não se tinha registro e controle de todos os procedimentos realizados na Unidade.

O aumento nos registros tem sido utilizado pela SMS-Curitiba como um indicador de melhoria na qualidade do atendimento nas Unidades de Saúde. No entanto, o depoimento dos próprios profissionais de saúde esclarecem a questão, deixando claro que o número de consultas médicas não aumentou após a informatização, apenas os registros foram sistematizados: “...a princípio, aumentou [registro de atendimentos]...porque ao mesmo tempo que entrou o sistema, a informatização, aumentou a nossa área de abrangência" (Auxiliar de Enfermagem); “o sistema privilegia os registros e não a qualidade no atendimento" (Médico, Unidade de Saúde 30); “a gente tá com problema porque... a gente não tem médicos. Então a gente tem muito mais usuários do que médicos na Unidade. Então os pacientes se obrigam a vir mais cedo pra conseguir consulta" (Auxiliar de Enfermagem 7, Unidade de Saúde 19); “com o sistema informatizado você tem a tua agenda fechada ... e você tem que ter os dezesseis atendimentos... eu acho que é pouco, eu acho que tinha que rever o tempo de atendimento na Unidade. Se você quer um serviço de qualidade, se você quer um atendimento minimamente razoável com o paciente, você não pode reduzir o tempo, você não tem como atender em menos tempo" (Médico 1, Unidade de Saúde 13); "o fornecimento de números à SMS ficou mais ágil, mas a humanização do usuário (o cuidado com o usuário) ficou de lado" (Auxiliar de Enfermagem 2); “aumentou a demanda e não aumentaram os profissionais; principalmente médicos" (Médico, Unidade de Saúde 30). 
O depoimento do auxiliar de enfermagem é claro quando afirma que "o fornecimento de números à SMS ficou mais ágil, mas a humanização do usuário (o cuidado com o usuário) ficou de lado". Revela-se aí mais um indicador da precarização da qualidade do atendimento assistencial nas Unidades de Saúde. O que se tem privilegiado no momento são os números apresentados à sociedade, mas o número de médicos e consultas disponíveis aos usuários/pacientes não foi alterado como revelado no depoimento deste auxiliar de enfermagem: "a gente não tem médicos (...) tem muito mais usuários do que médicos na Unidade”.

Outra questão pesquisada tem relação com a existência ou não de prioridade no atendimento dentro das Unidades de Saúde. A Tabela 1 mostra que $83,8 \%$ dos profissionais acreditam que há prioridade no atendimento de pessoas com necessidades imediatas. A prioridade a que se referem, está inserida no processo de triagem, chamada avaliação inicial, regulamentado pelo manual de procedimentos do "acolhimento solidário" 11 e sistematizado pelo programa informatizado, no qual os pacientes são encaminhados de acordo com a necessidade. Consultas para o mesmo dia, consultas agendadas ou emergências são encaminhadas de maneiras diferentes.

No entanto, os profissionais afirmam que é difícil priorizar necessidades imediatas, se considerarmos que o computador não revela nem de imediato, nem nunca, a necessidade do paciente. Somente durante a "avaliação inicial" é que o profissional vai avaliar as reais necessidades do paciente; até este momento, o paciente estará esperando com os demais usuários para ser atendido. A não ser que o paciente demonstre estado grave de saúde, o que caracteriza um caso de emergência, e nesse caso, será encaminhado para unidades de atendimento 24 Horas ou para hospitais conveniados, ou ainda, que seja identificado como paciente de risco e incluído em programas de atenção continuada.

Em função de tais obstáculos, muitos profissionais afirmaram categoricamente que "o sistema não permite atender às pessoas com necessidades imediatas" (Auxiliar de Enfermagem, Unidade de Saúde 14), pois “pelo computador é difícil saber quem precisa mais do atendimento... são apenas nomes..." (Auxiliar de Enfermagem, Unidade de Saúde 13).

Com relação aos programas de atenção continuada, $76,2 \%$ dos profissionais discordam de que o sistema informatizado tenha dificultado o acesso dos usuários. São programas de apoio às gestantes, hipertensos, lactentes, diabéticos etc. $\mathrm{O}$ que os profissionais ressaltam é que os programas ainda não estão adequados ao atendimento, são muito complexos, possuem muitas telas a serem preenchidas e requerem um tempo maior para adaptação dos que os manuseiam. Como mostra o depoimento deste médico (Unidade de Saúde 13): “os programas de hipertenso, de diabético ... de certa maneira ele [sistema] é confuso, difícil, muitas telas...".

A burocracia no processo de atendimento médico nas Unidades também foi objeto desta pesquisa. Cabe esclarecer que a burocracia na forma como foi questionada aos profissionais, refere-se à negação da formulação ideal típica weberiana 12,13 , que a define como estratégia de eficiência para as organizações formais. Tratase, portanto, do conceito utilizado pelo senso comum que apreende "burocracia" mais como obstáculo do que estratégia de êxito das organizações. Cumpre destacar que, para Weber, a burocracia se caracteriza como um dos indicadores do predomínio da racionalidade instrumental em todos os espaços da vida moderna.

Isto posto, a intenção é verificar até que ponto as estratégias utilizadas para buscar maior eficiência no atendimento à população estão de acordo com a realidade deste serviço, ou ainda, com o objetivo primordial de humanizar o atendimento. Humanizar no sentido de tratar o ser humano como sujeito, como senhor de sua própria existência, não como coisa, como objeto, enfim, como máquina.

A Tabela 1 mostra que $81,1 \%$ dos profissionais concordam que ainda há "burocracia” no atendimento. $\mathrm{O}$ "acolhimento solidário" e a informatização do sistema de atendimento implementaram algumas exigências para o acesso do usuário ao atendimento nas Unidades. Exigências como cadastro atualizado do usuário, bloqueio de área, presença do paciente para marcar consulta, são utilizadas como formas de regulamentar o atendimento, organizá-lo para que se possa ter um melhor controle "gerencial" do processo, portanto, maior eficiência e eficácia. No entanto, alguns profissionais contestam estes procedimentos adotados: "se o sistema fosse direcionado menos à "burocracia" e mais à assistência ficaria bom" (Médico, Unidade de Saúde 25). O depoimento mostra que de alguma forma as práticas burocráticas, ao invés de atender no sentido "humanizador" à população carente do seu município ou região, distanciam as Unidades do seu objetivo apresentado publicamente como primordial.

No caso da saúde, as estratégias burocráticas utilizadas podem estar proporcionando maior eficiência gerencial, mas não têm dado garantias de qualidade e resolutividade no atendimento à saúde do município. 
Os dados e depoimentos, portanto, não estão totalmente de acordo com a proposta de “acolhimento solidário" que segue: "O acolhimento significa a humanização do atendimento, o que pressupõe a garantia de acesso a todas as pessoas (acessibilidade universal). Diz respeito, ainda, à escuta de problemas de saúde do usuário, de forma qualificada, dando-lhe sempre uma resposta positiva e responsabilizando com a resolução do seu problema. Por conseqüência, o acolhimento deve garantir a resolutividade (sic!) que é o objetivo final do trabalho em saúde, resolver efetivamente o problema do usuário. A responsabilização para com o problema de saúde vai além do atendimento propriamente dito, diz respeito também ao vínculo necessário entre o serviço e a população usuária" (Merhy apud Shimazaki et al. 14, p. 67).

Ao que parece, não há correspondência entre o que está proposto e os depoimentos de alguns profissionais, corroborando as conclusões de Faria 15 acerca do abismo entre discurso ético e prática nas relações de poder no interior das organizações formais. Muito do que é "dito", em termos de possíveis decisões "socialmente responsáveis", é veementemente negado na ação propriamente realizada. Este abismo entre discurso e prática tende a transformar políticas públicas em autênticas "cartas de intenções” com pouca ou nenhuma correspondência com o mundo da vida.

O depoimento que segue confirma o argumento a partir do momento que relata que "o distrito solicita um tipo de relatório, mas o sistema não fornece, portanto, ainda mantemos controles à parte, em papel, pastas, para que possamos atender à demanda da própria SMS" (Auxiliar de Enfermagem, Unidade de Saúde 26). No sentido de regulamentar e legitimar os procedimentos administrativos, o sistema informatizado, no momento, ainda não está em conformidade com os procedimentos realizados no dia-a-dia. Modificou-se a gestão dos procedimentos internos das Unidades, mas não houve integração dos demais órgãos da SMSCuritiba.

Os médicos, que tradicionalmente decidiam por conta própria, passaram a prestar contas de seus atos, procedimentos e condutas técnicas aos gerentes hospitalares, que são cada vez mais estranhos à área médica propriamente dita, ou seja, são profissionais com formação em áreas diversas. Com instrumentos administrativos eficientes e modernos, esses gerentes, objetivando maior eficiência e eficácia, passam a controlar o movimento clínico, administrativo e burocrático nos hospitais. Esta é uma nova cultura organizacional progressivamente im- plementada nas modernas organizações de saúde. "As organizações complexas são estruturalmente mais burocráticas do que as profissionais e ameaçam a autonomia dos profissionais especializados. A burocracia tende a tratá-los como trabalhadores de fábrica no que se refere às condições de trabalho e à ordenação das funções $e$ papéis" 16 (p. 139).

Outro suposto indicador de qualidade no atendimento médico diz respeito à formação de filas de espera nas Unidades. A Tabela 1 mostra que $87,5 \%$ dos profissionais concordam que ainda há filas de espera para o atendimento nas Unidades. Embora a intenção inicial do programa tenha sido de agilizar o fluxo de atendimento, reduzindo as filas, os depoimentos que seguem mostram o contrário: "quando a avaliação está demorando e a fila na recepção aumenta, a chefia reclama e vem ver por que estou demorando... não podemos deixar formar fila ... é um caos" (Auxiliar de Enfermagem, Unidade de Saúde 22); “eu procuro atender o melhor possível o paciente... pode ter fila lá fora,não me importo... todos serão atendidos da mesma forma; infelizmente terão que esperar. Se acharem ruim [SMS] então que coloquem mais auxiliares para atender a população. Eu vou fazer meu trabalho bem feito" (Auxiliar de Enfermagem, Unidade de Saúde 22); “é limitado o número de equipamentos - uma impressora para todos os computadores...o serviço acumula e formam-se filas... computador 286 é muito lento" (Auxiliar de Enfermagem, Unidade de Saúde 6).

Embora a maioria dos depoimentos mostre que os profissionais estão trabalhando sobpressão constante no sentido de atender e "despachar" o paciente no menor tempo possível, quando o profissional diz "eu procuro atender o melhor possível o paciente, pode ter fila lá fora, não me importo, todos serão atendidos da mesma forma...", mostra que o comprometimento com a qualidade ainda é mantido por alguns profissionais, mesmo sob pressão. Revelando que eles próprios percebem que é importante "que coloquem mais auxiliares para atender a população”. Uma reivindicação de que seja reconhecida a necessidade dos profissionais no desempenho de sua função. São poucos profissionais para muitos pacientes.

As Unidades continuam cheias no dia-adia, com pessoas que aguardam horas na Unidade para passar pela avaliação inicial e marcar uma consulta. Quando o profissional diz que "as filas saíram de fora para dentro da Unidade de Saúde" (Auxiliar de Enfermagem, Unidade de Saúde 18), ele está afirmando que houve alteração apenas na forma dos pacientes esperarem. 
Interessante observar que $74,7 \%$ dos profissionais concordam que após a informatização ficou mais fácil marcar consultas com especialistas. As consultas especializadas são agendadas pelo sistema on-line, muitas vezes pelo próprio médico durante a consulta. Quando há vaga disponível no sistema, o paciente sai do consultório com o dia, a hora e local de sua consulta especializada. Quando não há vaga o profissional agenda a consulta, deixando o paciente na fila de espera, sendo avisado quando a consulta for efetivamente marcada.

$\mathrm{O}$ que facilitou foi o agendamento das consultas. Agora não mais cabe aos profissionais a responsabilidade de conseguir as consultas, uma vez que são agendadas pelo sistema central de marcação. Percebe-se, então, que para o profissional houve uma facilitação no processo de trabalho, no entanto, "para o usuário existe ainda a fila virtual" (Auxiliar de Enfermagem, Unidade de Saúde 27) e "a fila virtual é muito grande!" (Auxiliar de Enfermagem, Unidade de Saúde 25).

"No começo, quando implantou o sistema, consultava,marcava consulta na hora e pronto... o paciente vinha, fazia tudo e saia com tudo pronto. Hoje em dia, já tem uma fila imensa de espera, quer dizer, não resolveu nada. Eles estão esperando da mesma forma" (Auxiliar de Enfermagem 5, Unidade de Saúde 18).

A demanda por consultas especializadas é maior que a disponibilidade de médicos conveniados. Ainda há muita espera para consultas e exames especializados.

\section{Considerações finais}

O presente artigo apresenta indicadores de que a introdução da tecnologia informacional computadorizada compromete a qualidade no atendimento, ou melhor dizendo, compromete a qualidade na relação entre profissional de saúde-paciente.

Verifica-se com a pesquisa que a relação entre profissional de saúde e paciente tornouse mais distante com a introdução do sistema informatizado. Com relação a este dado, observa-se uma preocupação maior dos médicos. Neste particular, o computador poderia ser comparado a um intruso no relacionamento entre profissional-paciente, é como se o tempo do médico fosse "seqüestrado pela máquina".

Portanto a ruptura do laço entre profissional e paciente põe em dúvida a qualidade do atendimento pois contraria o conceito de que, para haver qualidade no serviço, todos os clientes, funcionários e comunidade devem estar satisfeitos.

Muitas alterações de ordem tecnológica mas poucas de ordem operacional, muitas máquinas mas poucos profissionais para atender os usuários. Em muitos casos, observa-se a manutenção de filas ou ainda, a criação de filas "virtuais".

Outros indicadores da precariedade podem ser citados como: o número de consultas não compatível com o aumento na demanda das Unidades; a "burocracia" no atendimento ao invés de atender no sentido "humanizador" à população carente do seu município ou região, distanciam as Unidades do seu objetivo apresentado publicamente como primordial.

No caso da saúde, as estratégias burocráticas utilizadas podem estar proporcionando maior eficiência gerencial, mas não têm dado garantias de qualidade e resolutividade no atendimento à saúde do município.

Neste contexto, a presença do computador em cima da mesa, como se demarcasse uma barreira tecnológica entre o profissional de saúde e o paciente ou, mais especificamente, entre o médico e o paciente, interfere na relação e desumaniza o atendimento.

O contraste entre humanização e desumanização no atendimento está presente no depoimento de uma auxiliar de enfermagem quando diz: "parece mais um 'atropelamento solidário' e não 'acolhimento solidário"'. Um depoimento revelador da precarização da qualidade no atendimento médico das Unidades de Saúde. Um atendimento que privilegia a quantidade em detrimento da qualidade. 


\section{Resumo}

No setor de serviços, o produto do trabalho não é uma mercadoria que possa ser facilmente trocada. O que se vende é um serviço especializado e este se dá, basicamente, pela troca de informações, pelo atendimento às necessidades e expectativas do usuário que o procura. Então o que se sobressai são relações sociais entre indivíduos:profissionais e usuários/consumidores. Sendo assim, o artigo apresenta indicadores de que a introdução da tecnologia informacional computadorizada precariza a qualidade na relação profissional de saúdelpaciente. Inicialmente, este artigo traz uma discussão acerca dos conceitos de qualidade do setor de saúde. A relação profissional de saúdelpaciente é o próximo assunto a ser discutido, passando por um breve histórico do conceito saúde/doença e considerações sobre como está sendo vislumbrada a relação médicopaciente,especificamente. A análise dos dados primários mostra alguns indicadores de que as mudanças tecnológicas, físicas e de gestão nas Unidades de Saúde, estão precarizando a qualidade no atendimento à saúde. Muitas alterações de ordem tecnológica, mas poucas de ordem operacional, muitas máquinas, mas poucos profissionais para atender os usuários.

Qualidade dos Cuidados de Saúde; Serviços de Saúde; Tecnologia

\section{Referências}

1. Serapioni M. Avaliação da qualidade em saúde : a contribuição da sociologia da saúde para a superação da polarização entre a visão dos usuários e a perspectiva dos profissionais de saúde. Saúde em Debate 1999; 23:81-92.

2. Carr DK, Littman ID. Excelência nos serviços públicos: gestão da qualidade total na década de 90. Rio de Janeiro: Qualitymark; 1992.

3. Tauile JR. Automação microeletrônica e competitividade: tendências no cenário internacional. In: Schmitz H, Carvalho RQ, organizadores. Automação, competitividade e trabalho: a experiência internacional. São Paulo: Editora Hucitec; 1988.

4. Andreassi T. Inovação em serviços: desafios e oportunidades. Jornal da Ciência 2002; 25 jan.

5. Almeida LG. Qualidade: introdução a um processo de melhoria. Rio de Janeiro: Qualitymark; 1995.

6. Barbosa SL, Faria JH. Comprometimento: uma avaliação crítica sobre a práxis organizacional. Florianópolis: Enampad; 2000.

7. Lakatos EM, Brutscher SM. O conceito saúdedoença analisado através dos tempos e a prática previdenciária no Brasil. Saúde em Debate 2000; 24:75-89.

8. Cotta RMM, Minardi M, Muniz JN, Mendes FF, Cotta Filho JS. O município e a nova lógica institucional do setor saúde: uma análise empírica do cenário local. Saúde em Debate 1999; 23:54-62.

9. Machado MH. Trabalhadores da saúde: um bem público. Saúde em Debate 1995; 48:54-7.
10. Maciel-Lima SM. Trabalho e tecnologia: efeitos da tecnologia informacional sobre o trabalho no setor de saúde [Dissertação de Mestrado]. Curitiba: Setor de Ciências Sociais Aplicadas, Universidade Federal do Paraná; 2002.

11. Secretaria Municipal de Saúde de Curitiba. Manual de práticas de enfermagem: a saúde de braços abertos. Curitiba: Secretaria Municipal de Saúde, Prefeitura Municipal de Curitiba; 1999.

12. Weber M. Ensaios de sociologia. 4a Ed. Rio de Janeiro: Zahar; 1970.

13. Weber M. Os pensadores. 2a Ed. São Paulo: Abril Cultural; 1980.

14. Shimazaki ME. Acolhimento Solidário : a saúde de braços abertos. In: Ducci L, Simão MG, Pedotti MA, Moysés SJ, organizadores. Curitiba: a saúde de braços abertos. Rio de Janeiro: Centro Brasileiro de Estudos da Saúde; 2001; p. 63-77.

15. Faria JH. Ética, moral e democracia: os paradoxos da práxis organizacional. Curitiba: Universidade Federal do Paraná; 2000.

16. Machado MH. Gestão do trabalho em saúde no contexto de mudanças. Rev Adm Pública 2000; 34:133-46.

Recebido em 24/Mar/2003

Versão final reapresentada em 29/Ago/2003

Aprovado em 23/Out/2003 